\title{
Methodology of laser processing for precise control of surface micro-topology
}

\author{
M. Ahmed Obeidi, E. McCarthy, D. Brabazon \\ Advanced Processing Technology Research Centre, \\ School of Mechanical \& Manufacturing Engineering, \\ Dublin City University, Dublin 9, Ireland
}

\begin{abstract}
Laser surface texturing of materials potentially offers precise control of surface structure and mechanical properties. This has a wide range of applications such as control of frictional forces, control of bond strength in interference fit joints, and production of antifouling surfaces. To achieve such texturing in a well-defined, useful manner, precise control of the applied laser processing parameters over a sizeable surface area is required. This paper presents the development of a method for creating highly repeatable and predetermined moiré textured patterns on metallic samples via laser processing. While the method developed is broadly applicable to various materials and laser systems, in the example detailed here the surfaces of cylindrical stainless steel samples were processed with a pulsed $\mathrm{CO}_{2}$ laser. The resulting modified surfaces contained texture geometries with pre-definable peak-to-peak widths, valleyto-peak heights, and texture directions. The method of achieving this theoretically and experimentally is detailed in this paper. The relationship between the laser processing parameters and resulting diameter increase was confirmed via Design of Experiment response surface methodology. Precise control of the laser textured cylindrical surface outer diameter and texture pattern are key factors in determining the potential suitability of this process for application to
\end{abstract}


the production of interference fit fasteners. The effects of the laser processing parameters and topologies of the resulting re-solidified metal profile on the surfaces were assessed in detail with a focus on this application.

Keywords Surface texturing, $\mathrm{CO}_{2}$ laser, micro-profiling, micro-texturing, stainless steel, moiré pattern. 


\section{INTRODUCTION}

Laser surface texturing is used as a beneficial processing method for piston sleeves in order to reduce friction. Etsion et al. showed that a fuel saving of $4 \%$ can be achieved by producing a micro-dimpled surface using laser texturing on diesel engine piston rings [1]. By taking into account the number of cars using diesel engines in just the United States, the diesel fuel saving would be around 120 million barrels/year [2]. Experimental work has shown that ideal situation of hydrodynamic lubrication can be achieved when the aspect ratio of the laser texture (micro dimple depth/diameter) is between $0.01-0.1[1,3-5]$. Due to the high degree adjustability of the laser processing parameters, accurate control of the dimensions of the processed surface in terms of ablation, melting, and heat affected zone (HAZ) can be achieved $[1,2,4,5]$. The level of precision achievable in this regard via laser processing is impossible to be achieved using conventional machining methods.

For many industrial applications, surface roughening is sought for certain locations on the part to be processed, while retaining the core bulk material properties unchanged. The texturing of the piston rings is one example of this. Another example is the different levels of roughness required for hip implants, where the implant stem often requires micrometer level roughness to allow for implant bonding into the body, and the ball head has to be very smooth in order to allow for free movement. Laser texturing can also be used to inhibit the adhesion of undesirable biological elements to implants. Infections are a common source of implant failure [6,7]. The presence of bacteria or biofilms on the implant can lead to infection, and also inhibit osseointegration [8]. Cunha et al. investigated the use of laser surface texturing on titanium to reduce the adhesion of Staphylococcus aureus and biofilm formation [9]. They observed that the laser textured surfaces 
had a lower bacteria adhesion than the untreated surfaces, due size of the surface features, and the distance between them, being smaller than the size of the bacteria. The authors contrasted this method with alternative methods where a coating of an antimicrobial agent, such as copper, silver nitrate, silver, titanium, or drug-functionalised nanoparticles, were deposited on the surface of the implant. These methods potentially introduce toxic elements to the patient's body which laser surface texturing does not, making it potentially a safer anti-microbial surface preparation option. Further work on titanium implants, has been shown that laser processed surface can also be tailored to preferentially promoted human biospecies attachment and growth, indicating the higher levels of biocompatibility achieved from this processing [10].

Advances in laser technology have allowed for new types of surface texturing to be achieved such as submicron-scale ripples called laser induced periodic surface structures (LIPSS) [11-13]. These ripple patterns arise from interference between the incident radiation and surface electromagnetic waves, and are highly dependent on polarisation [14]. These small scale and highly uniform patterns mirror textures seen in nature (e.g.: the lotus leaf), and can be suitable for applications such as self-cleaning surfaces, structural colouring, and antireflective surfaces. Laser surface texturing can be used to alter the hydrophobicity of a surface [15-17]. Superhydrophobic surfaces have a number of applications, such as self-cleaning glass [18-20], drag reduction [21-23], and in microfluidic devices [24-26]. Ta et al. created superhydrophobic metal surfaces using laser surface texturing [15]. A $1064 \mathrm{~nm}$ SPI fibre laser was scanned over the surface of copper and brass substrates, creating textured surfaces that were initially hydrophilic but aged to become superhydrophobic reaching a maximum contact angle $\left(152^{\circ}\right)$ after 11 days. The authors attributed this effect to the surface roughness created by the laser texturing, and the 
change over time in surface chemistry. Thus the method proved to be an effective, direct write, fast-processing, and low waste method of modifying the wettability of metal surfaces.

An application which has not yet been investigated, is the use of laser surface texturing for interference fit connections. Interference fit connections are typically formed via the high frictional force generated between a shaft and hub. This is produced via the forcing of an oversized pin or dowel into a mated drilled hole. These connections require high insertion forces and tight tolerances on the diameters of the shaft and hub, and often suffer from excessive plastic deformation which can lead to premature failure of the joint [27]. Laser surface texturing allows for precise control of the outer diameter of the shaft, as well as defined interference volume from control of the surface texture. In interference fit joints, a key factor is the interference value, defined as the difference between the hole diameter and the diameter of the insert. The strength of the joint is dependent on the interference value such that very high machining accuracy is required. Commercially available interference fit pins have typical tolerances in the range \pm 0.0045 to $0.08 \mathrm{~mm}$. For example, a typical interference fit fastener (DRIV-LOK knurled pin) has a nominal interfering diameter $9.881 \pm 0.076 \mathrm{~mm}$ and is recommended for interfering with a hole diameter of $9.576 \pm 0.051 \mathrm{~mm}$, giving a positive interference ranging from 0.178 to 0.432 $\mathrm{mm}$. While within this range of positive interference, good bonding would be expected, a significant difference in the level of plastic deformation and associated bond strength is expected from such difference in levels of interference. Controlled diameter increases through laser texturing could provide an easier and less expensive method of achieving such precise diameters. The increased control over the overall interfering volume could also prevent the excessive plastic deformation noted from conventional interference fit joints, thereby providing a more reliable joint. 
There has been some examination into the control of surface topography by laser treatment. $\mathrm{Du}$ et al. characterised the laser texturing of rollers by Nd:YAG, investigating the relation of the input parameters to surface roughness and hardness of the texture [28]. Vilhena et al. investigated the creation of micropore textures on steel surfaces [29]. They related the laser parameters to the micropore profiles, and tested the sliding wear behaviour. However, the use of laser texturing for finely controlling the generated surface pattern and increase in pin diameter

for interference fit fasteners has not previously been presented. In this paper, we therefore present a novel method for prescribing the texture before laser processing, and setting the laser parameters to achieve this texture after processing.

\section{MATERIAL AND METHODS}

Figure 1 shows a schematic diagram of the laser process utilised in this study. The cylindrical pin samples were rotated with a DC motor which was used to provide an adjustable speed range from 0 to $5000 \mathrm{rpm}$. The carrying stage provided translational speed within the range of 0 to $5000 \mathrm{~mm} / \mathrm{min}$. A computerised numerical control (CNC) $\mathrm{CO}_{2}$ laser machine Rofin DC-015 of $1.5 \mathrm{~kW}$ maximum average power and a laser beam focus diameter of $0.2 \mathrm{~mm}$ were utilised. Argon gas was delivered in line with the laser beam during processing. The role of this assist gas was to protect the laser focusing lens from the laser-induced plasma, which may harm the lens, and to provide an inert gas surrounding to reduce surface oxidation of the sample. The pin sample was supported by a freely rotating centre bearing opposite to the DC motor, to prevent sample off centre spinning. 
Stainless steel 316L cylindrical pin samples were used in this study to examine the effect of laser process control parameters on generated surface textures. Cylindrical samples were employed instead of flat samples, as this allowed for higher scanning speeds, resulting from the interacting angular and translational speeds. This provided a suitable shape for an interference fit pin as one possible final application. The as-received samples were 10,12, 16, and $20 \mathrm{~mm}$ in diameter, and were cut into lengths to allow translational scans of $10 \mathrm{~mm}$ length along the pin with different laser processing parameters. The laser parameters examined were the power (W), pulse repetition frequency PRF (Hz), and the percentage of overlapping laser spots (\%). An important measured outcome response was the increase in the samples' diameters $(\mathrm{mm})$. This increase in diameter results from the controlled surface melting and re-solidification. In order to improve the laser energy absorption, samples were sandblasted which increased the surface roughness to approximately $1.5 \mu \mathrm{m}$.

The assist gas pressure was tested at different levels. The increase in metal surface thickness and the presence of oxidation, roughness, and moire pattern were recorded. The assessment test of the effect of gas pressure was conducted using laser processing parameters of $500 \mathrm{~W}, 300 \mathrm{~Hz}$, and $-20 \%$ overlap. From this test, an optimum argon gas pressure of $0.3 \mathrm{MPa}$ was identified which resulted in reduced oxide formation but also lower levels of gas consumption. This pressure level was applied for the rest of the samples produced in this study which resulted in better definition and visualisation of the generated patterns due to the reduced occurrence of surface oxide. A block scheme for the experiment can be found in Figure 2. 


\subsection{Control of micro-texture longitudinal and circumferential dimensions}

Three possible laser spot overlap scenarios are shown on the schematic in Figure 3. Zero overlap indicates that the laser spots in both circumferential and axial directions were arranged such that they touch only tangentially, as shown in Figure 3 (b). Positive overlap occurs where the laser spots interfere with each other by a certain defined percentage, as indicated in Figure 3 (a), and conversely negative overlap indicates the presence of unprocessed gaps between each successive laser spot, Figure 3 (c). For each of these cases in this work, the rotational and translation speed were set such that the laser spots were overlapped to the same extent in the circumferential and longitudinal directions. The mathematical relationship between translation and rotational speed required to achieve these overlaps is presented below. A negative overlap test sample to compared the spot size and theoretical pre-determined spot spacing was prepared with a laser power of $200 \mathrm{~W}, \mathrm{PRF}$ of $100 \mathrm{~Hz}$, and spot overlapping of $-50 \%$.

\section{Zero overlap scenario}

Dividing the pin's circumference by the spot diameter to find the number of spots per one revolution of the pin gives the number of pulses/rev $=\pi \mathrm{D} / \mathrm{d}$; where $\mathrm{D}$ is the pin's diameter $(\mathrm{mm})$ and $\mathrm{d}$ is the laser beam spot diameter $(\mathrm{mm})$. Multiplying by the number of revolutions per second, $\omega$ (rpm)/60, gives the PRF (pulses per second) which results in zero overlap as follows.

$$
\mathrm{PRF}=\pi \mathrm{D} \omega /(60 \mathrm{~d})
$$




\section{For any other overlap percentage scenario}

The value for negative or positive overlap (OV) must be added to the latter equation to produce the correct PRF for other overlap situations as follows.

$$
\mathrm{PRF}=\pi \mathrm{D} \omega(1+\mathrm{OV} \%) /(60 \mathrm{~d})
$$

Hence, the tangential (circumferential) overlap percentage is given as,

$$
\mathrm{OV} \%=\left[\frac{\mathrm{PRF} \times 60 \times d}{\pi \times D \times \omega}-1\right] \times 100
$$

and the linear translation speed of the stage, $\mathrm{V}_{\mathrm{L}}$, relative to the fixed laser beam to give the same value of overlap in the axial direction can be calculated as

$$
\mathrm{V}_{\mathrm{L}}=\mathrm{d} \times \omega \times(1-\mathrm{OV} \%)
$$

\subsection{Control of diameter dimensional change via laser micro-texturing}

The melt pool size depends on the set laser power, spot size, traverse speed, pulse repetition frequency (PRF), and percentage overlap. The interaction between the circumferential and longitudinal speeds and the pulse repetition frequency contributes to form the pattern generated in both the circumferential and longitudinal directions. The developed moiré pattern thereby has prescribed peak-to-peak widths, as well as peak-to-valley heights, see Figure 4 (a). The helical translation of the beam spot on the pin surface, under the wide range of possible processing parameters, provides a wide range of scanning and overlapping variations. The re-solidified molten pools construct different surface patterns with texture angle, $\theta_{\mathrm{p}}$, see Figure 4 (b). 


\subsection{Calculating the texture pattern angle}

From Figure 5, the laser beam path on the cylinder surface is represented by the thin lines. This scanning direction is from the bottom to the top due to the rotational movement of the cylindrical sample. The thick lines represent the pattern valleys generated by the incident laser pulses and re-solidified melted pools. The circumferential distance that the laser beam travels from point A to point $\mathrm{B}$ (distance $\mathrm{X}_{\mathrm{C}}$ ), can be calculated as

$$
\mathrm{X}_{\mathrm{C}}=\mathrm{V}_{\mathrm{C}} \times \text { time for each pulse }=(\pi . \mathrm{D} . \omega / 60) \times(1 / \mathrm{PRF})
$$

where $\mathrm{D}$ is the diameter of the cylindrical metal sample in millimetres, $\mathrm{Vc}$ is the tangential speed in $\mathrm{mm} / \mathrm{s}, \omega$ is the rotational speed in revolutions per minute, and PRF is the frequency in pulses per second. Similarly, in order for the laser beam to travel from point A to point $\mathrm{C}$, the sample must complete one full revolution and move a distance longitudinally of

$$
\mathrm{X}_{\mathrm{L}}=\mathrm{V}_{\mathrm{L}} \times \text { time required for one revolution }=\mathrm{V}_{\mathrm{L}} \times(60 / \omega)
$$

where $\mathrm{V}_{\mathrm{L}}$ is the linear speed in mm/s. A number of test samples were accordingly produced, using the parameters listed in Table I, to investigate the geometry given by different levels of overlap.

Applying these equations on samples Ov-1 and Ov-2 listed in Table I, results in $\mathrm{X}_{\mathrm{C}}=0.2 \mathrm{~mm}$, $\mathrm{X}_{\mathrm{L}}=0.2 \mathrm{~mm}$, and a pattern angle of $45^{\circ}$ for sample Ov-1; $\mathrm{X}_{\mathrm{C}}=0.166 \mathrm{~mm}, \mathrm{X}_{\mathrm{L}}=0.158 \mathrm{~mm}$, and pattern angle of $46^{\circ}$ for sample Ov-2; and $\mathrm{X}_{\mathrm{C}}=0.25 \mathrm{~mm}, \mathrm{X}_{\mathrm{L}}=0.23 \mathrm{~mm}$ and pattern angle of $47.4^{\circ}$ for sample Ov-3. These are compared later to experimental results in section 3.1

In equations (4) and (5) the inclination in the laser path when travelling from Point A to Point B

was neglected and the distance $|\mathrm{AB}|$ was counted as a vertical displacement. As a validation of 
this assumption, the following Figure 5 which shows a detailed sketch for $\triangle \mathrm{ABC}$ in Figure 5 is examined.

From Figure 5, $\mathrm{X}_{\mathrm{L}}$ is the longitudinal component and $\mathrm{X}_{\mathrm{C}}$ is the circumferential component of the displacement. $\mathrm{X}_{\mathrm{L}}$ can be considered the possible error in taking $\mathrm{X}_{\mathrm{L}}$ as the longitudinal component and can be calculated as follows: $X_{\dot{L}}=U(\mathrm{~mm} / \mathrm{sec}) \times$ time for each pulse $(1 / \mathrm{PRF})$ (sec); where $U$ is the laser spot scan speed, the resultant speed of the two components, the linear $\mathrm{V}_{\mathrm{L}}$ and the tangential speed $\mathrm{V}_{\mathrm{C}}$. Applying this equation on all the experimental parameters used in this study and calculating $X_{\check{c}}$ gives negligible (less than $9 \times 10^{-6} \mathrm{~mm}$ ) differences between $X_{\check{c}}$ and $\mathrm{X}_{\mathrm{C}}$, which supports the method of vertical displacement calculation detailed above.

The effects of the processing parameters were examined according to a $3^{3}$ factorial design of experiment. The parameters levels utilised are listed in Table II. From screening experiments, these laser processing parameters were chosen to be slightly above the melting threshold of SST 316L. High powers were avoided to ensure minimal material loss via ablation, surface oxidation, and resulting negative extreme changes in pin dimensions and mechanical properties.

The following parameters were fixed during sample preparation. The duty cycle was fixed to $50 \%$, and the focal position was set $1 \mathrm{~mm}$ below the sample surface which resulted in an incident defocused spot size of $0.2 \mathrm{~mm}$ on the sample surface. From these conditions, a clearly visible moiré pattern was achieved on all produced surfaces. Ten measurements of each sample diameter were taken using a Vernier gauge of $0.05 \mathrm{~mm}$ resolution. Ten measurements were also taken to determine the average peak-to-peak widths and peak-to-valley heights with a Keyence VHX2000E 3D digital microscope with a measurement resolution below $1 \mu \mathrm{m}$. The average and 95\% confidence interval of the resultant dimensional measurements increases were calculated. 
Pearson correlation coefficients were calculated between the input parameters and output responses.

\subsection{Numerical modelling of laser generated thermal profile}

From Fourier's law, the thermal energy needed to initiate surface melting is equal to $C_{p} \times\left(T_{m^{-}}\right.$ $T_{o}$ ); where $C_{p}$ is the specific heat for stainless steel, $500 \mathrm{~J} / \mathrm{kg} . \mathrm{K}, \mathrm{T}_{\mathrm{m}}$ and $\mathrm{T}_{\mathrm{o}}$ are the melting temperature, $1445^{\circ} \mathrm{C}$, and the surrounding temperature respectively. These values give a specific energy of $711.5 \mathrm{~kJ} / \mathrm{kg}$ required for melting. Laser parameters applied during a melt volume assessment test were a power of $200 \mathrm{~W}$, PRF of $100 \mathrm{~Hz}$, duty cycle of $50 \%$, laser beam focus diameter of $0.2 \mathrm{~mm}$, and an applied negative overlap of $-50 \%$ so that the gaps between laser incident pulses could be clearly measured. Stainless steel density, $\rho$, and thermal diffusivity, $\alpha$, of $8000 \mathrm{~kg} / \mathrm{m}^{3}$ and $3.8 \times 10^{-6} \mathrm{~m}^{2} / \mathrm{s}$ respectively were used [30]. Using these values along with the pulse width, $\tau$, of $5 \mathrm{~ms}$ allows calculation of diffusion length as $(\alpha \times \tau)^{0.5}=\left(3.8 \times 10^{-6} \times 5 \times 10^{-}\right.$ $\left.{ }^{3}\right)^{0.5}=137.8 \mu \mathrm{m}$. Approximating the volume of metal melted as a cylindrical volume of diameter equal to the laser beam spot size of $0.2 \mathrm{~mm}$ and a depth of $137.8 \mu \mathrm{m}$, then the mass affected by the laser beam can be calculated as $\rho \times$ volume $=8000 \times \pi \times\left(0.1 \times 10^{-3}\right)^{2} \times 137.8 \times 10^{-6}=3.46 \times 10^{-8} \mathrm{~kg}$. Multiplying this mass by the specific energy gives $24.64 \mathrm{~mJ}$ of energy which is required by each laser pulse for surface melting. This is a useful initial approximation of energy required for surface melting. A more detailed mathematical model adopted in this study for a time-dependent pulsed laser beam with a PRF in pulses per second is presented in Equation 6 [31].

$$
\mathrm{T}(\mathrm{x}, \mathrm{y}, \mathrm{z}, \mathrm{t})=\mathrm{T}_{\mathrm{o}}+\frac{P(t)}{2 \pi k r} \exp \left[i \omega t+\frac{U}{2 \alpha}\left(x-r \sqrt{1+\frac{4 \alpha \omega i}{U^{2}}}\right)\right]
$$


where $\mathrm{P}(\mathrm{t})$ is the time-dependent laser power; $\omega$ is the fundamental frequency $=2 \pi \mathrm{PRF} ; \mathrm{r}$ is the

radial distance from the heat source, $\sqrt{x^{2}+y^{2}+z^{2}} ; \alpha\left(\mathrm{m}^{2} / \mathrm{s}\right)$ is the thermal diffusivity; $\mathrm{k}$ $\left(\mathrm{W} / \mathrm{m} \cdot \mathrm{C}^{\circ}\right)$ is the thermal conductivity of the material; and $\mathrm{T}(\mathrm{x}, \mathrm{y}, \mathrm{z}, \mathrm{t})$ is the time dependant temperature at the given coordinates. As noted previously, for the processing conditions used in this work, there is little difference between $\mathrm{U}$ and $\mathrm{V}_{\mathrm{c}}$, and either can be used in this model without significant error. This model was previously developed and tested by Issa et al. [32] and Aqida et al. [33].

\subsection{Metallography}

A sample was sectioned in the longitudinal and transverse direction as shown in the following Figure 7, using a wire EDM CNC machine. Wire cutting method was preferred compared to other machining methods, in order to avoid excessive damage on the laser processed area, and to reduce the subsequent amount of grinding and polishing needed. A Buehler Motopol 2000 was used for the grinding and polishing process. The grinding was carried out by applying successive grades of silicon carbide paper of 400,600, 800 and 1200, with a water flow to act as a lubricant, and for flushing the loose metal and abrasive particles. Final polishing was carried out using a Textmet cloth with diamond and alumina suspensions of $9,6,3$, and $0.05 \mu \mathrm{m}$ particle size sequentially. Each polishing grade was applied for 3 to 4 minutes with rotational speed of 150 rpm. In order to enhance the visual contrast of grain boundaries, the polished layer was chemically etched. Stainless steel 316L, as an austenitic steel alloy, is significantly anti-corrosive and is difficult to etch. An effective etchant from Adler, made up of 9 grams copper ammonium 
chloride, $150 \mathrm{ml}$ hydrochloric acid, 45 grams hydrated ferric chloride, and $75 \mathrm{ml}$ distilled water was applied to the sample surface for 8 to 10 seconds using a cotton cloth, before rinsing with isopropyl alcohol (IPA). The micrographs were taken using a Reichart ME F2 optical microscope.

\section{RESULTS}

\subsection{Measured micro texture longitudinal and circumferential dimensions}

Figure 8 shows micrographs of a test cylindrical sample surface processed using a power of 200 $\mathrm{W}, \mathrm{PRF}$ of $100 \mathrm{~Hz}$, and spot overlapping of $-50 \%$. The large negative overlap provided distinct, well-spaced melt pools. This allowed for examination of the relationship between the laser parameters, and the melt pool geometry and pattern. These laser processing parameters were just sufficient to melt small thin regions on the pin surface. An optical micrograph of the re-solidified melt pools is shown in Figure 8 (a), and a SEM image of an individual melt pool in Figure 8 (b). The melt pool is observed to be $200 \mu \mathrm{m}$ in the longitudinal direction and $360 \mu \mathrm{m}$ in the circumferential direction. A separation of $100 \mu \mathrm{m}$ was measured between melt pools in both directions.

Figure 9 shows the cross sectional micrographs of the melt pool for the same sample shown in Figure 8. Figure 9 (a) shows the circumferential cross section and the corresponding melt pool length in this direction. Figure 9 (b) shows the longitudinal cross section and the corresponding length of the melt pool in this direction. The melt pool dimensions are observed to be $345 \mu \mathrm{m}$ in the circumferential direction and $200 \mu \mathrm{m}$ in the longitudinal direction. Figure 9 (c) shows a 
longitudinal cross sectional view at the maximum melt pool depth, $70 \mu \mathrm{m}$, as well as the distance between subsequent melt pools, $100 \mu \mathrm{m}$, which agrees well with the result in Figure 8 (b).

\subsection{Measured diameter dimension changes after laser micro texturing}

The samples produced are divided into two profile types: Ridged, where a regular helical pattern of ridges is visible (see Figure 11 (a)), and Textured, where there is a repeating texture but no clear ridged pattern (see Figure 11 (b)). A Keyence VHX2000E 3D digital microscope was used to determine the average peak-to-peak widths and peak-to-valley heights. Figures 12, 13 and 14 show graphs of the average diametrical increase, the peak-valley and the peak-peak values with the $95 \%$ confidence interval for samples, with corresponding DoE input conditions listed in Table 2. The response surface for the increased pin diameter is plotted against the laser processing conditions for $20 \%$ OV with two ridge samples no. 13 and 20 fall in this range, see Figure 15. The error bars around each point represent the $95 \%$ confidence intervals.

For the ridged samples, the average peak to peak distance, the average peak to valley heights between ridge peaks were measured as described in section 2.2, see Figure 4. For the Textured samples, the average peak to valley height was measured as the distance between the maximum and minimum surface heights locally around the laser impact positions.

\subsection{Measuring the texture pattern angle}

The resultant surface textures were characterised with SEM, see Figure 10. Figure 10 shows the resultant textures from samples (a) Ov-1, (b) Ov-2, and (c) Ov-3, see Table I. The resulting texture pattern angles were measured as $45^{\circ}, 46^{\circ}$ and $47.5^{\circ}$ respectively which correspond excellently with the theoretical calculations found in section $2.3,45^{\circ}, 46^{\circ}$ and $47.4^{\circ}$. From microstructural and macroscopic examination, no cracking was observed in the samples. 


\subsection{Calculated thermal profiles}

Figure 16 show the temperature profile for a single laser pulse at $78 \mu \mathrm{m}$ depth from the surface. This result was generated from simulation with the model presented in equation 5 and input parameters of $200 \mathrm{~W}, 100 \mathrm{~Hz}, 2.5 \mathrm{~ms}$ residence time, and $50 \%$ duty cycle. The temperatures here show that at this depth there is only a small region in which the temperature is above the melt temperature, $1445{ }^{\circ} \mathrm{C}$. This corresponds well with the micrograph in Figure 9 (c) which was recorded at the same set of laser processing conditions.

\subsection{Metallography results}

The results from the metallography methods described in Section 2.5 are shown in Figure 9. This figure shows as expected the longer melt pool in the circumferential direction compared to the longitudinal direction. The distance between melt pools in the longitudinal direction can also be clearly recorded, as per Figure 9 (b).

\section{Discussion}

The processing parameters applied on the sample represented in Figure 8 where the surface was locally melted with negative overlap, correspond to each laser pulse delivering an energy of 1000 mJ. Since most metals and alloy surfaces are reasonably reflective to the longer-wavelength infrared light beams, such as $\mathrm{CO}_{2}$ laser [34-36], the energy supplied must be several times that 
calculated based solely on consideration of heat capacity, latent heat of fusion, and latent heat of vaporisation. Quintino et al. [35] noted for example that iron absorbs about 5\% of the energy from the $\mathrm{CO}_{2}$ laser radiation, while steel absorb closer to $12 \%$. As noted in section 2.4 the corresponding energy required for melting a cylindrical volume at the surface was approximated as $24.64 \mathrm{~mJ}$. This indicates that only approximately $2.46 \%$ of the heat energy delivered was absorbed by the metal surface. A close examination of the re-solidified melt pool shape shows that it resembles an ellipse rather than a circle, even though the beam is TEM $_{\mathrm{oo}}$ Gaussian which should be circular. The elliptical shape can be understood to be due to the moving of the sample during laser firing. This means that the HAZ must be corrected. Moreover, the mass affected by the laser energy also need to be recalculated to the exact melt depth of $70 \mu \mathrm{m}$ found experimentally, see Figure 9 (c). Taking this into account and recalculating, the new affected mass should be closer to $3.16 \times 10^{-8} \mathrm{~kg}$, and the corresponding heat energy needed to melt this mass would be $22.5 \mathrm{~mJ}$. This indicates that the approximation used was acceptable.

These absorption factor values are still lower than expected, compared to those reported by Quintino et al. [35] for iron (5\%) and steel (12\%). This could be explained by stainless steel, as an alloy, being more reflective than other types of steel at the same wavelength, and it would therefore be expected to reflect a larger percentage of the incident visible and IR radiation than pure steel.

An assumption adopted in this consideration is that the heat loss to the surrounding by convection and radiation is negligible, and that all the absorbed pulse energy is converted into heat energy. This assumption is reasonable because the melting process is carried out in such a short time, equal to one pulse width of $5 \mathrm{~ms}$. Moreover, the PRF value of $100 \mathrm{~Hz}$ is the minimum value applied in this study, see Table II. The PRF of 200 and $300 \mathrm{~Hz}$ would result in pulse 
widths of 2.5 , and $1.6 \mathrm{~ms}$ respectively, thus reducing the process time and not allowing sufficient time for significant heat loss to the surroundings, which supports the assumption adopted here.

The gaps between the molten pools seen in Figures 8 and 9, in both the circumferential and the axial directions, were found to be $100 \mu \mathrm{m}$. This value is half of the laser beam spot diameter of $0.2 \mathrm{~mm}$, which is consistent with the controlled overlap value of $-50 \%$. These gaps were consistent during the entire scanning process. The melt pool circumferential spot length, expanded to $360 \mu \mathrm{m}$ in the beam propagation direction due to the high circumferential speed of $2400 \mathrm{~mm} / \mathrm{min}$, see Figure 8 . The distance scanned by each pulse can be calculated as the pulse width times the scanning speed $=0.005 \mathrm{~s} \times(2400 / 60) \mathrm{mm} / \mathrm{s}=200 \mu \mathrm{m}$. For the $200 \mu \mathrm{m}$ diameter laser spot to translate $200 \mu \mathrm{m}$, the total processed surface length would be $400 \mu \mathrm{m}$. The measured melt pool is $40 \mu \mathrm{m}$ shorter than this which could be considered to be due to the time needed for heat energy to build up before melting is initiated. This explanation is supported by the melt pool longitudinal length, see Figure 8 (b), which is narrower where the laser shot begins than where it finishes. It is considered that energy accumulation is required before being sufficient for melting. The dimensions discussed are taken from both optical microscope and SEM, the results which were consistent with each other. As discussed, the dimensions observed agree well with what is expected from the laser parameters, which supports the ability to predict and produce a pre-determined texture with this technique. The maximum melt depth measured experimentally for the sample shown in Figure 8, matched reasonably well with the thermal model prediction, both of which indicated similar melt depth of $70 \mu \mathrm{m}$ and $78 \mu \mathrm{m}$ (Figures 8 and 14) respectively. The $8 \mu \mathrm{m}$ difference between the experimental and the modelled melt depth may be due to the assumption of no heat loss to surrounding which was adopted in the mathematical model. 
The correlation strength between the diameter as a response and the main laser processing parameters was calculated using the Pearson correlation coefficient, see Figure 17. The diameter increase is most notably inversely proportional to the pulse repetition frequency due to the corresponding increase in heating time and pulse period which leads to a larger melt pool size. This effect was also observed by Kumar [37]. Moreover, similar correlation strength was exhibited for both the fluence and the pulse energy, while lower correlations were noted with energy density (e), laser power (a) and percentage overlap (c). The low correlation with energy density can be understood as the energy density is a function of the scanning speed and that the processed depth decreases as the scanning rate increases [37,38].

The depth of the treated layer can influence the mechanical part's lifetime, and as such it is essential to control this. An average treated layer thickness of 40 to $60 \mu \mathrm{m}$ is regarded as very good $[39,40]$. The new modified layer will have altered mechanical properties due to the phase transformation from austenite to martensite, which is caused by the high cooling rates of between $10^{3}$ to $10^{6} \mathrm{~K} / \mathrm{s}$ [41]. Typically, this change will result in increased hardness and wear resistance, due to the presence of the martensite, though this should be confirmed for specific operational conditions.

Figure 10 show SEM images of three samples produced with the same laser power and PRF, but with differing percentage overlap (see Table I). The $0 \%$ and $20 \%$ overlap samples exhibit a spiral patterning, visible even to the naked eye. The sample with the $20 \%$ overlap was found to have a lower porosity. For the $0 \%$ overlap, an average peak to peak width and peak to valley height of $1,500 \mu \mathrm{m}$ and $165 \mu \mathrm{m}$ respectively were measured. For the $20 \%$ overlap, an average width and height of 1,400 $\mu \mathrm{m}$ and $180 \mu \mathrm{m}$ respectively were recorded. These peak-to-valley heights are smaller than the observed diameter increase of $750 \mu \mathrm{m}$ recorded for the same parameters applied 
on sample no. 20 in Figure 12. The lowest points in the post-treatment pin diameter are therefore higher than the initial diameter of the pin. This suggests that there are two components to the expanded pin diameter: 1 . the build-up of melted and solidifying ridged during the microtexturing, and 2. an expansion of the melted and re-solidified material due to the formation of a more porous microstructure. The peak-to-valley heights and widths were also measured for the samples where a clear pattern was observable and showed the ranges of 135 to $641 \mu \mathrm{m}$ and 340 to $1500 \mu \mathrm{m}$ respectively, see Figures 13 and 14 .

The presentation of the experimental data from Figure 12 is shown as response surface graphs in Figure 15. This more clearly shows the main effects, as well as the interacting effects of the laser power applied and the frequency, for one percentage overlap of $20 \%$ as an example. The best results were found to be achieved with low PRF values, coupled with moderate or high power levels. The application of a high laser power in conjunction with a low PRF value would result in a larger amount of molten material, due to the higher average power and pulse energy. This in turn should result in larger increases in a samples diameter. Interestingly, the negative overlaps produced more re-solidification build-up and overall diameter increase, in comparison with the positive overlap processing. This may be due to a smoothing of the previous molten scanned layer by the subsequent scan. From Figure 15, at a power level of $400 \mathrm{~W}$ and PRF of $100 \mathrm{~Hz}$, the melt pool could be expected to be large, for both the current and the previous scans. However, the diameter increase was only $0.8 \mathrm{~mm}$, sample no. 10 in Figure 12 . When the frequency was increased to $200 \mathrm{~Hz}$, the pulse energy would be reduced from 2 to $1 \mathrm{~J}$, and similarly the pulse width reduced from 5 to $2.5 \mathrm{~ms}$. A reduction in the melt pool size resulted, and less material removal by the gas jet, thus an increase in micro texture thickness was noted, see sample no. 27 in Figure 12. The same scenario is repeated when moving to the highest frequency value, 300 
$\mathrm{Hz}$, the reduction in the pulse energy and the melt pool size is continued. A reduction in microtexture thickness would be resulted this time due to the smaller melt pool size, not material jetting, which is caused by the smaller amount of thermal energy delivered, see sample no. 15 in Figure 12.

\section{Conclusion}

Laser surface texturing has a number of established and potential applications, such as in friction control, medical implants, hydrophobic surfaces, and interference fit joints. For these applications high control of the surface texture, through control of the laser parameters, is required. For the interference fit application focus of this paper, a high level of control of the outer diameter and pattern of the laser processed pins is required.

In this work, high-speed $\mathrm{CO}_{2}$ laser texturing of stainless steel $316 \mathrm{~L}$ cylindrical samples was carried out to study the interactive patterning effects of laser pulses on the surface and the resultant overlapping patterns in both the circumferential and longitudinal directions. Such interaction patterns result in moiré patterns with unique and very useful resulting geometries. The main laser processing parameters employed in this study were the beam power, pulse repetition frequency, scanning speed, and the overlapping of the scans. Controlled laser pulses cause localised melting and texture pattern building of material, due to convection and overlapping scans before re-solidification of the surface, thereby altering its surface morphology. Examination of a sample textured with a "negative" overlap allowed confirmation of the expected melt pool size and shape, as well as spacing of the melt pools in the circumferential and longitudinal directions. These results agreed well with the thermal model. The energy density 
threshold required to trigger melting for the 316L SST surface was determined to be in the range $22-25 \mathrm{~J} / \mathrm{mm}^{2}$.

A range of samples were textured for a $3^{3}$ factorial DoE, and the post-textured sample diameters were measured. For interference fit joints, a key factor is the interference value, defined as the difference between the hole diameter and the diameter of the insert. Control over the outer diameter and texture pattern via the laser processing parameters should be strongly related to suitability of the technique for interference fit fasteners.

The resultant increase in sample diameter was between $0.41 \mathrm{~mm}$ and $1.03 \mathrm{~mm}$, and the correlation with the laser parameters was investigated. This increase in diameter, the predetermined nature of the pattern, and the modified geometry are predictable, repeatable, and well controlled by the processing parameters. This novel micro-profiling method of laser texturing could find application across a number of industries, including in the defined strength interference fit joints that are used within the transportation industry.

\section{Acknowledgments}

The authors would like to thank the funding agency Enterprise Ireland for funding this work under grant CF/2014/2619. 


\section{References}

[1] I. Etsion, E. Sher, Improving fuel efficiency with laser surface textured piston rings, Tribol. Int. 42 (2009) 542-547. doi:10.1016/j.triboint.2008.02.015.

[2] Y. Gao, B. Wu, Y. Zhou, S. Tao, A two-step nanosecond laser surface texturing process with smooth surface finish, Appl. Surf. Sci. 257 (2011) 9960-9967. doi:10.1016/j.apsusc.2011.06.115.

[3] I. Etsion, State of the Art in Laser Surface Texturing, J. Tribol. 127 (2005) 248. doi:10.1115/1.1828070.

[4] I. Etsion, G. Halperin, V. Brizmer, Y. Kligerman, Experimental Investigation of Laser Surface Textured Parallel Thrust Bearings, Tribol. Lett. 17 (2004) 295-300. doi:10.1023/B:TRIL.0000032467.88800.59.

[5] G. Ryk, Y. Kligerman, I. Etsion, a. Shinkarenko, Experimental Investigation of Partial Laser Surface Texturing for Piston-Ring Friction Reduction, Tribol. Trans. 48 (2005) 583-588. doi:10.1080/05698190500313544.

[6] M.E. Török, N.P.J. Day, Staphylococcal and streptococcal infections, Med. (United Kingdom). 42 (2014) 1-7. doi:10.1016/j.mpmed.2013.10.016.

[7] P. Astagneau, C. Rioux, F. Golliot, G. Brücker, Morbidity and mortality associated withsurgical site infections: results from the 1997-1999 INCISO surveillance, J. Hosp. Infect. 48 (2001) 267-274. doi:10.1053/jhin.2001.1003.

[8] G. Subbiahdoss, R. Kuijer, D.W. Grijpma, H.C. van der Mei, H.J. Busscher, Microbial biofilm growth vs. tissue integration: "the race for the surface" experimentally studied., Acta Biomater. 5 (2009) 1399-404. doi:10.1016/j.actbio.2008.12.011.

[9] A. Cunha, A.-M. Elie, L. Plawinski, A.P. Serro, A.M. Botelho do Rego, A. Almeida, M.C. Urdaci, M.-C. Durrieu, R. Vilar, Femtosecond laser surface texturing of titanium as a method to reduce the adhesion of Staphylococcus aureus and biofilm formation, Appl. Surf. Sci. 360 (2016) 485-493. doi:10.1016/j.apsusc.2015.10.102.

[10] E. Chikarakara, P. Fitzpatrick, E. Moore, T. Levingstone, L. Grehan, C. Higginbotham, M. Vázquez, K. Bagga, S. Naher, D. Brabazon, In vitro fibroblast and pre-osteoblastic cellular responses on laser surface modified Ti-6Al-4V., Biomed. Mater. 10 (2015) 15007. doi:10.1088/1748-6041/10/1/015007.

[11] J.V. Obona, V. Ocelík, J.Z.P. Skolski, V.S. Mitko, G.R.B.E. Römer, A.J. Huis, J.T.M. De Hosson, Applied Surface Science On the surface topography of ultrashort laser pulse treated steel surfaces, Appl. Surf. Sci. 258 (2011) 1555-1560. doi:10.1016/j.apsusc.2011.09.130.

[12] J.V. Obona, V. Ocelík, J.C. Rao, J.Z.P. Skolski, G.R.B.E. Römer, J.V. Obo, A.J. Huis, J.T.M. De Hosson, Applied Surface Science Modification of $\mathrm{Cu}$ surface with picosecond laser pulses, 303 (2014) 118-124. doi:10.1016/j.apsusc.2014.02.104. 
[13] U. Kalsoom, S. Bashir, N. Ali, Surface \& Coatings Technology SEM , AFM , EDX and $\mathrm{XRD}$ analysis of laser ablated Ti in nonreactive and reactive ambient environments, Surf. Coat. Technol. 235 (2013) 297-302. doi:10.1016/j.surfcoat.2013.07.056.

[14] F.A. Müller, C. Kunz, S. Gräf, Bio-Inspired Functional Surfaces Based on Laser-Induced Periodic Surface Structures, Materials (Basel). 9 (2016). doi:10.3390/ma9060476.

[15] D. V. Ta, A. Dunn, T.J. Wasley, R.W. Kay, J. Stringer, P.J. Smith, C. Connaughton, J.D. Shephard, Nanosecond laser textured superhydrophobic metallic surfaces and their chemical sensing applications, Appl. Surf. Sci. 357 (2015) 248-254. doi:10.1016/j.apsusc.2015.09.027.

[16] R. Wang, S. Bai, Effect of droplet size on wetting behavior on laser textured SiC surface, Appl. Surf. Sci. 353 (2015) 564-567. doi:10.1016/j.apsusc.2015.06.158.

[17] A.-M. Kietzig, S.G. Hatzikiriakos, P. Englezos, Patterned Superhydrophobic Metallic Surfaces, Langmuir. 25 (2009) 4821-4827. doi:10.1021/la8037582.

[18] C. Kapridaki, P. Maravelaki-Kalaitzaki, TiO2-SiO2-PDMS nano-composite hydrophobic coating with self-cleaning properties for marble protection, Prog. Org. Coatings. 76 (2013) 400-410. doi:10.1016/j.porgcoat.2012.10.006.

[19] D. Qi, N. Lu, H. Xu, B. Yang, C. Huang, M. Xu, L. Gao, Z. Wang, L. Chi, Simple approach to wafer-scale self-cleaning antireflective silicon surfaces., Langmuir. 25 (2009) 7769-72. doi:10.1021/la9013009.

[20] D. Kumar, X. Wu, Q. Fu, J.W.C. Ho, P.D. Kanhere, L. Li, Z. Chen, Development of durable self-cleaning coatings using organic-inorganic hybrid sol-gel method, Appl. Surf. Sci. 344 (2015) 205-212. doi:10.1016/j.apsusc.2015.03.105.

[21] R. Truesdell, A. Mammoli, P. Vorobieff, F. van Swol, C.J. Brinker, Drag Reduction on a Patterned Superhydrophobic Surface, Phys. Rev. Lett. 97 (2006) 44504. doi:10.1103/PhysRevLett.97.044504.

[22] S. Zhang, X. Ouyang, J. Li, S. Gao, S. Han, L. Liu, H. Wei, Underwater Drag-Reducing Effect of Superhydrophobic Submarine Model, Langmuir. 31 (2015) 587-593. doi:10.1021/la504451k.

[23] H. Park, G.Y. Sun, C.J. Kim, Superhydrophobic turbulent drag reduction as a function of surface grating parameters, J. Fluid Mech. 747 (2014) 722-734. doi:10.1017/jfm.2014.151.

[24] O.I. Vinogradova, A.L. Dubov, Superhydrophobic textures for microfluidics, Mendeleev Commun. 22 (2012) 229-236. doi:10.1016/j.mencom.2012.

[25] A. Tropmann, L. Tanguy, P. Koltay, R. Zengerle, L. Riegger, Completely superhydrophobic PDMS surfaces for microfluidics, Langmuir. 28 (2012) 8292-8295. doi:10.1021/la301283m.

[26] E. Gogolides, K. Ellinas, A. Tserepi, Hierarchical micro and nano structured, hydrophilic, 
superhydrophobic and superoleophobic surfaces incorporated in microfluidics, microarrays and lab on chip microsystems, Microelectron. Eng. 132 (2015) 135-155. doi:10.1016/j.mee.2014.10.002.

[27] G. Wachsmuth, M. Latzer, E. Leidech, Analytical computation of multiple interference fits under elasto-plastic deformations, ZAMM-ZEITSCHRIFT FUR Angew. Math. UND Mech. 94 (2014) 1058-1064.

[28] D. Du, Y.F. He, B. Sui, L.J. Xiong, H. Zhang, Laser texturing of rollers by pulsed Nd : YAG laser, J. Mater. Process. Technol. 161 (2005) 456-461. doi:10.1016/j.jmatprotec.2004.07.083.

[29] L. Vilhena, M. Sedlacek, B. Podgornik, J. Vizintin, A. Babnik, J. Mozina, Tribology International Surface texturing by pulsed Nd : YAG laser, Tribol. Int. 42 (2009) 14961504. doi:10.1016/j.triboint.2009.06.003.

[30] E. Klar, P. Samal, Powder Metallurgy Stainless Steels: Processing, Microstructures, and Properties, ASM International, 2007.

[31] J. Dowden, The Mathematics of Thermal Modeling: An Introduction to the Theory of Laser Material Processing, Chapman and Hall CRC, New York, 2001.

[32] A. Issa, D. Brabazon, M.S.J. Hashmi, 3D transient thermal modelling of laser microchannel fabrication in lime-soda glass, J. Mater. Process. Technol. 207 (2008) 307314. doi:10.1016/j.jmatprotec.2008.06.056.

[33] S.A.S.N. Aqida, S. Naher, D. Brabazon, Thermal Simulation of Laser Surface Modification of H13 Die Steel, Key Eng. Mater. 504-506 (2012) 351-356. doi:10.4028/www.scientific.net/KEM.504-506.351.

[34] P.A. Dearnley, A review of metallic, ceramic and surface-treated metals used for bearing surfaces in human joint replacements., Proc. Inst. Mech. Eng. H. 213 (1999) 107-135. doi:10.1243/0954411991534843.

[35] L. Quintino, A. Costa, R. Miranda, D. Yapp, V. Kumar, C.J. Kong, Welding with high power fiber lasers - A preliminary study., Mater. Des. 28 (2007) 1231-1237. doi:10.1016/j.matdes.2006.01.009.

[36] W. Steen, J. Mazumder, K.G. Watkins, Laser Material Processing, Springer, 1991.

[37] V.C. Kumar, Process parameters influencing melt profile and hardness of pulsed laser treated Ti-6Al-4V, Surf. Coatings Technol. 201 (2006) 3174-3180. doi:10.1016/j.surfcoat.2006.06.035.

[38] P. Jiang, X.L. He, X.X. Li, L.G. Yu, H.M. Wang, Wear resistance of a laser surface alloyed Ti-6Al-4V alloy, Surf. Coatings Technol. 130 (2000) 24-28. doi:10.1016/S02578972(00)00680-0.

[39] E. Chikarakara, S. Naher, D. Brabazon, High speed laser surface modification of Ti-6Al4V, Surf. Coatings Technol. 206 (2012) 3223-3229. doi:10.1016/j.surfcoat.2012.01.010. 
[40] B. Basu, D. Katti, A. Kumar, Advanced Biomaterials: Fundamentals, Processing, and Applications, Wiley-American Ceramic Society, 2009.

[41] T. Baker, H. Dong, Laser surface modification of Ti alloys, in: Surf. Eng. Light Alloy. Alum. Magnes. Titan. Alloy., Woodhead Publishing, 2009. 


\section{Tables}

Table I The laser processing applied to determine effect of overlap on sample morphology.

\begin{tabular}{|c|c|c|c|c|c|}
\hline $\begin{array}{c}\text { Sample } \\
\text { No. }\end{array}$ & $\begin{array}{c}\text { Power } \\
(\mathrm{W})\end{array}$ & PRF (Hz) & $\begin{array}{c}\text { Overlap } \\
(\% \mathrm{OV})\end{array}$ & $\begin{array}{c}\mathrm{V}_{\mathrm{L}} \\
(\mathrm{rpm})\end{array}$ & $(\mathrm{mm} / \mathrm{min})$ \\
\hline Ov-1 & 500 & 300 & 0 & 71.6 & 14 \\
\hline Ov-2 & 500 & 300 & 20 & 59.68 & 10 \\
\hline Ov-3 & 500 & 300 & -20 & 89.5 & 21 \\
\hline
\end{tabular}


Table II Range of laser processing parameters examined.

\begin{tabular}{|c|c|c|c|}
\hline $\begin{array}{c}\text { Sample } \\
\text { No. }\end{array}$ & $\begin{array}{l}\text { Power } \\
\text { (W) }\end{array}$ & $\begin{array}{l}\text { PRF } \\
(\mathrm{Hz})\end{array}$ & $\begin{array}{l}\text { Overlap } \\
(\% \mathrm{OV})\end{array}$ \\
\hline 1 & 400 & 300 & 0 \\
\hline 2 & 400 & 200 & -20 \\
\hline 3 & 300 & 200 & -20 \\
\hline 4 & 300 & 300 & -20 \\
\hline 5 & 300 & 300 & 0 \\
\hline 6 & 500 & 200 & -20 \\
\hline 7 & 300 & 100 & -20 \\
\hline 8 & 500 & 200 & 20 \\
\hline 9 & 400 & 100 & -20 \\
\hline 10 & 400 & 100 & 20 \\
\hline 11 & 500 & 300 & -20 \\
\hline 12 & 400 & 100 & 0 \\
\hline 13 & 300 & 100 & 0 \\
\hline 14 & 400 & 200 & 0 \\
\hline 15 & 400 & 300 & 20 \\
\hline 16 & 500 & 100 & 0 \\
\hline 17 & 300 & 200 & 0 \\
\hline 18 & 500 & 200 & 0 \\
\hline 19 & 500 & 300 & 0 \\
\hline 20 & 500 & 300 & 20 \\
\hline 21 & 300 & 200 & 20 \\
\hline 22 & 300 & 300 & 20 \\
\hline 23 & 500 & 100 & 20 \\
\hline 24 & 300 & 100 & 20 \\
\hline 25 & 400 & 300 & -20 \\
\hline 26 & 500 & 100 & -20 \\
\hline 27 & 400 & 200 & 20 \\
\hline
\end{tabular}




\section{Captions}

Figure 1 Schematic diagram for the $\mathrm{CO}_{2}$ laser scanning process of cylindrical samples.

Figure 2 Block scheme diagram for the experiment showing inputs and outputs

Figure 3 Schematic diagram illustrating the three possible scanning scenarios of (a) positive, (b) zero, and (c) negative laser spot overlap.

Figure 4 (a) Schematic diagram of the cross section view showing peak-peak width and peakvalley height, and (b) top view showing pattern direction relative to the longitudinal axis.

Figure 5 Schematic of laser path (thin lines) and resulting texture pattern (thick lines).

Figure 6 Schematic of three laser pulses showing the texture pattern angle $\theta_{\mathrm{p}}$.

Figure 7 Schematic for the sectioned cylindrical sample, cut by wire EDM.

Figure 8 Pictures of $316 \mathrm{~L}$ cylindrical sample scanned with $\mathrm{CO}_{2}$ laser beam of $200 \mathrm{~W}, 100 \mathrm{~Hz}$, $50 \%$ duty cycle, $2.5 \mathrm{~ms}$ residence time, and with $-50 \%$ overlap; (a) low magnification optical micrograph, and (b) high magnification SEM image.

Figure 9 Micrographs of 316L melt pool (a) circumferential cross section, (b) longitudinal cross sectional view, and (c) additional longitudinal cross section view showing maximum depth.

Figure 10 SEM images of sample surfaces (a) Ov-1, $0 \%$ overlap; (b) Ov-2, $20 \%$ overlap; and (c) Ov-3, $-20 \%$ overlap.

Figure 11 SEM images showing (a) ridged pattern processed with $500 \mathrm{~W}, 300 \mathrm{~Hz}$ and $20 \%$ overlap (sample 20), and (b) a non-ridged textured sample processed with $300 \mathrm{~W}, 300 \mathrm{~Hz}$ and $20 \%$ overlap (sample 4 ).

Figure 12 Graph of the average diametric increase of samples with the 95\% CI error bars $(n=8)$, for samples corresponding to Table 2 .

Figure 13 Graph of the peak-valley values of the processed samples with the $95 \%$ CI error bars $(\mathrm{n}=8)$, for samples corresponding to Table 2 .

Figure 14 Graph of the peak-peak values of the processed samples with clear pattern showing the $95 \%$ CI error bars ( $n=8)$, for samples corresponding to Table 2.

Figure 15 Diameter increase for the DoE laser processing parameters at the set overlap of $20 \%$ includes two ridge samples no. 20 and 23, for samples 8, 10, 15, 20, 21, 22, 24, 27 in Table 2.

Figure 16 (a) Objective, (b) top, and (c) side views for the temperature profile at $78 \mu \mathrm{m}$ depth for $316 \mathrm{~L}$ resultant from $200 \mathrm{~W}, 100 \mathrm{~Hz}, 2.5 \mathrm{~ms}$ residence time, and $50 \%$ duty cycle, for samples corresponding to Table 2 .

Figure 17 Graph of the correlation strength between the diameter increase and (a) laser power, (b) PRF, (c) percentage overlap, (d) pulse energy, (e) energy density, and (f) fluence, for samples corresponding to Table 2 . 
Figures

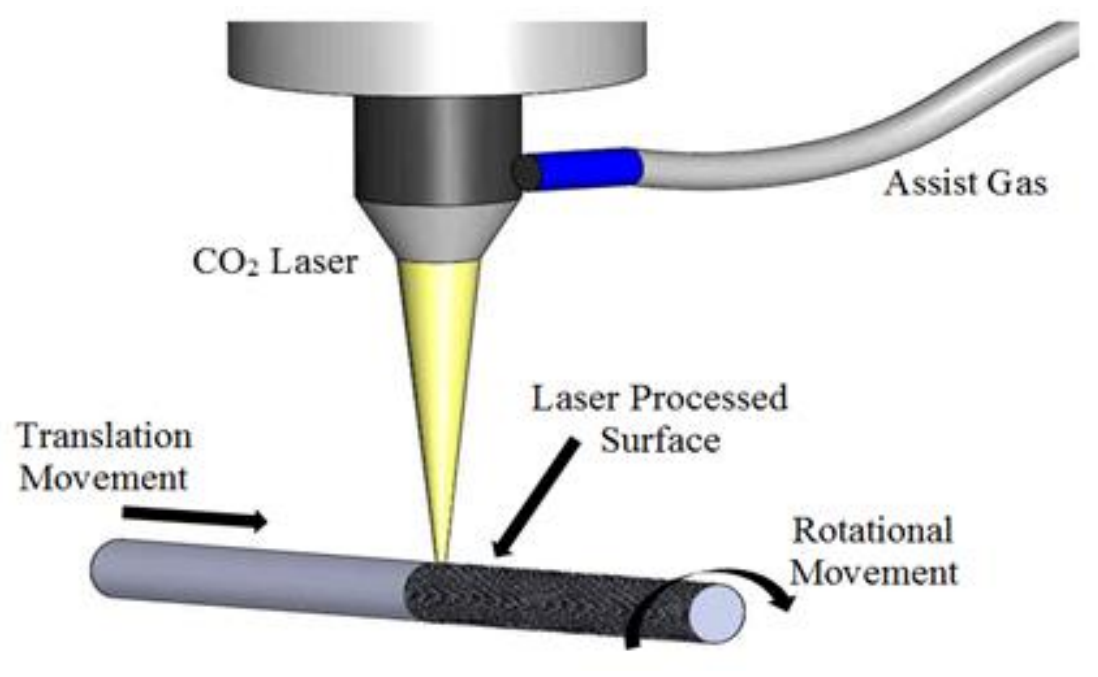




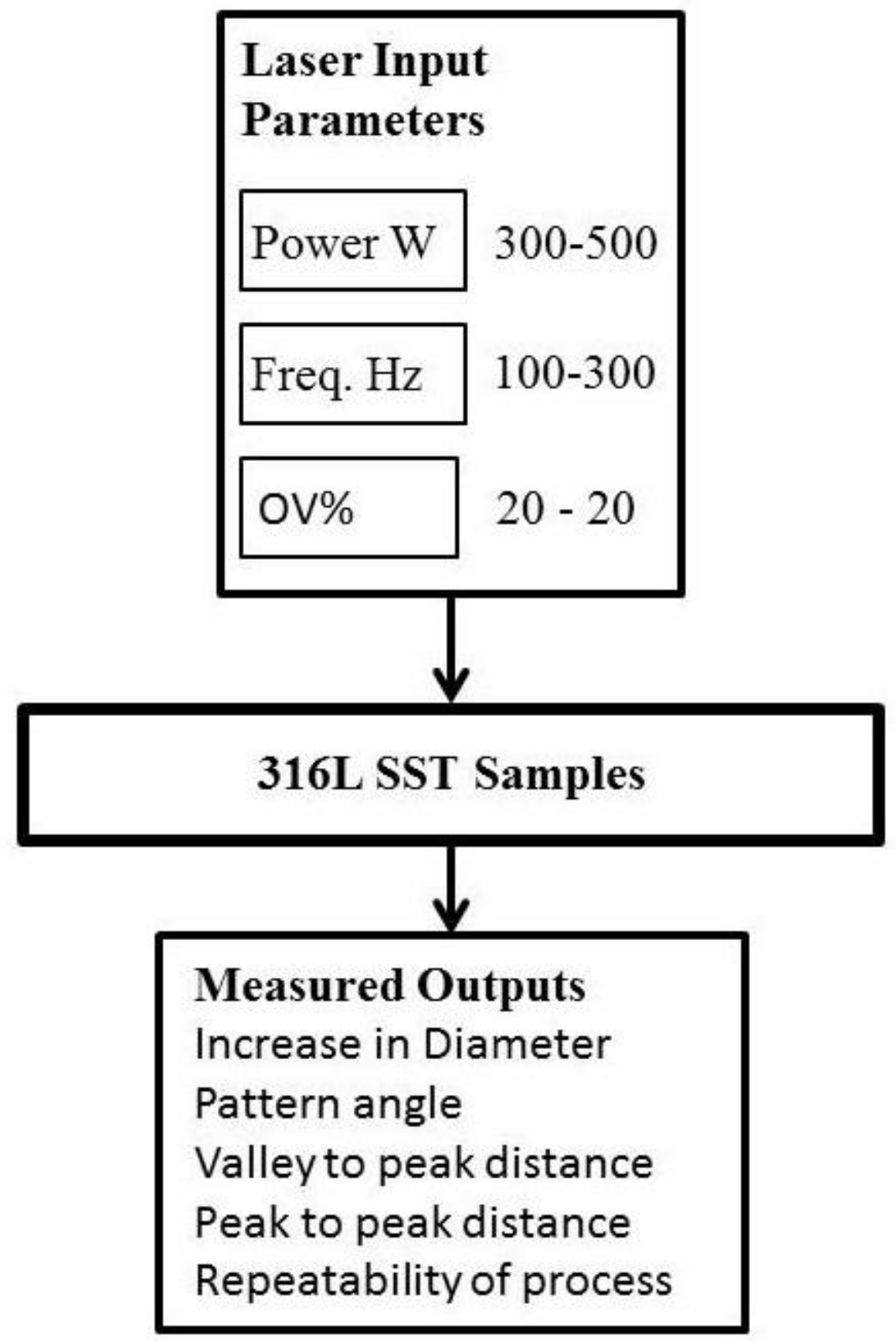




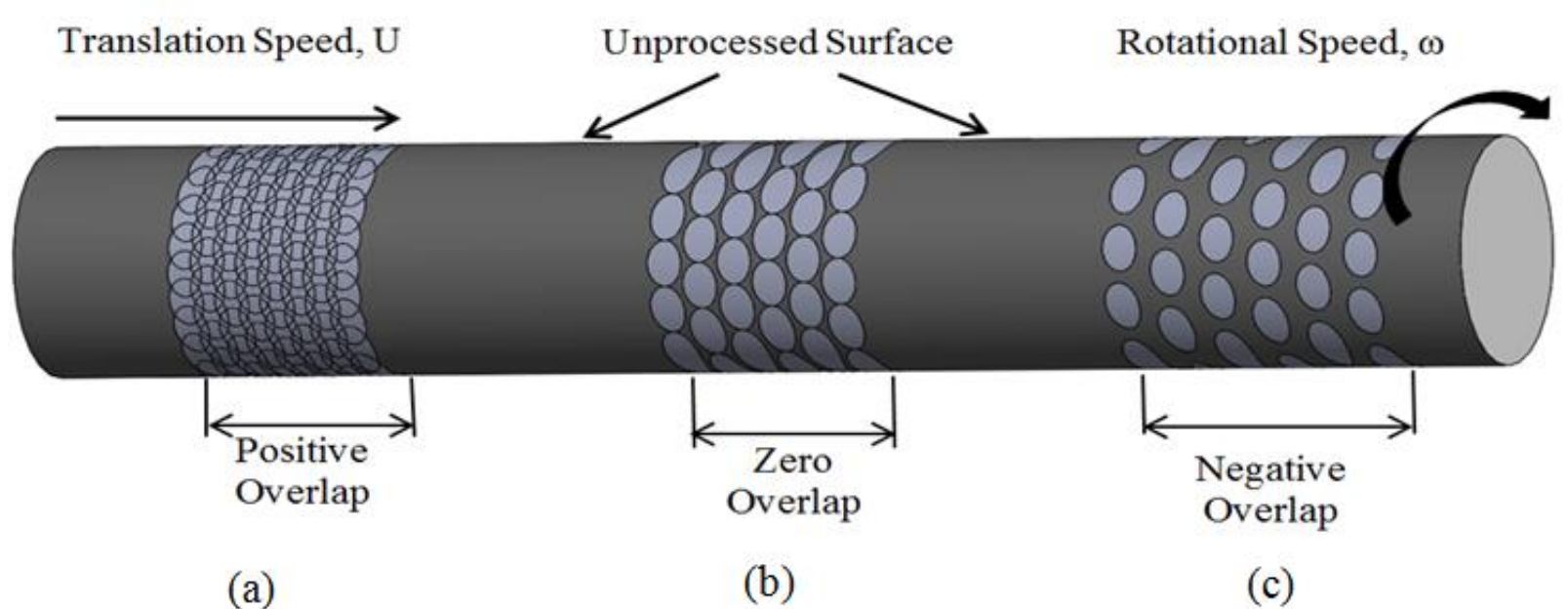




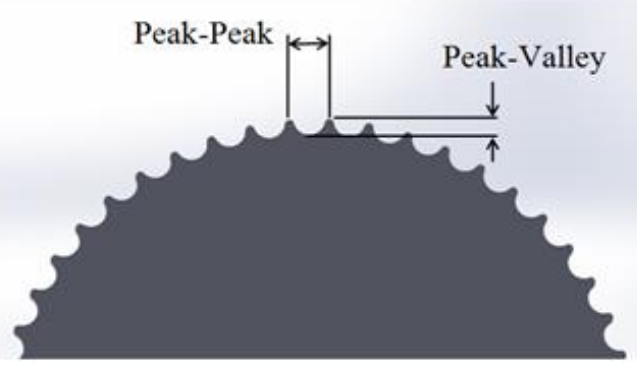

(a)

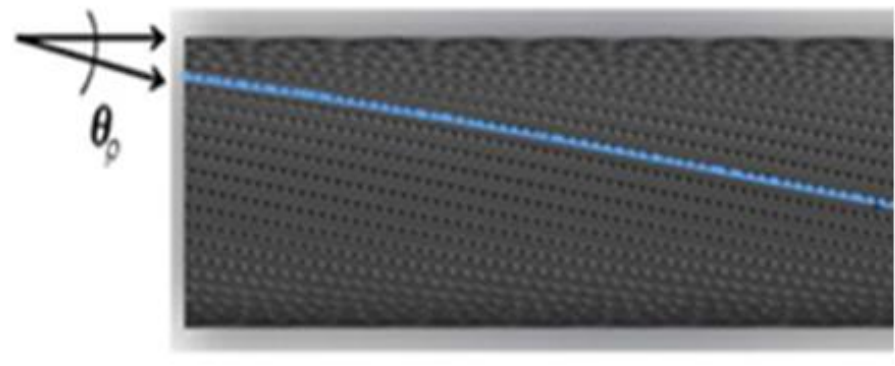

(b) 


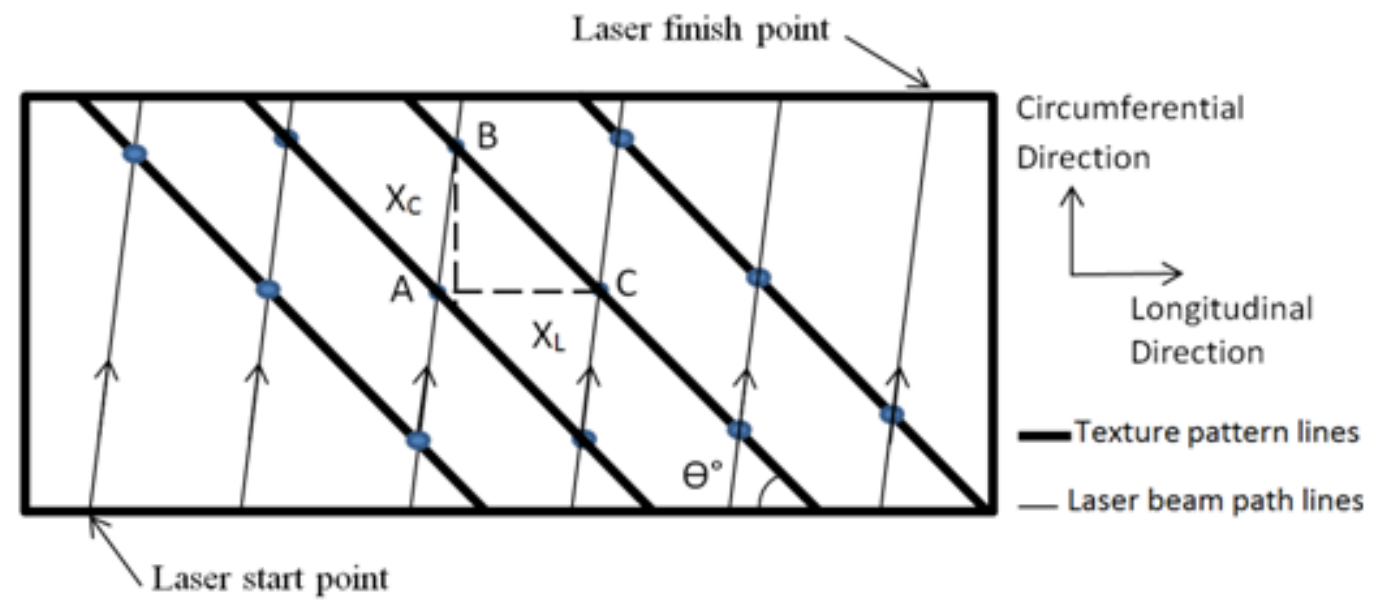




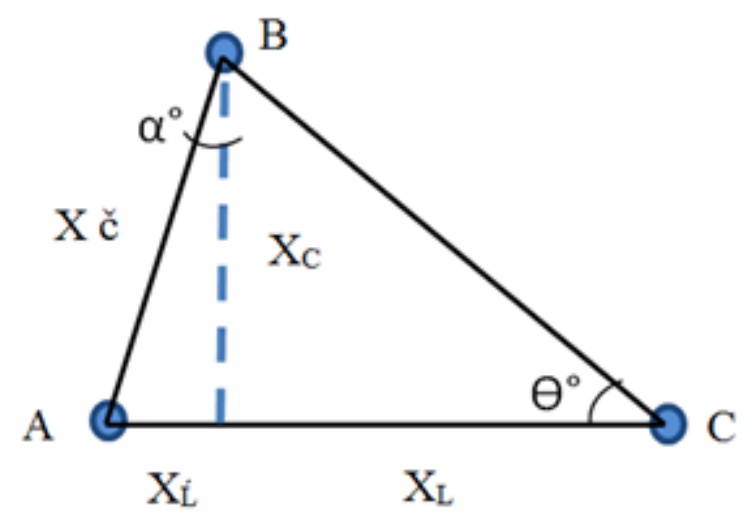




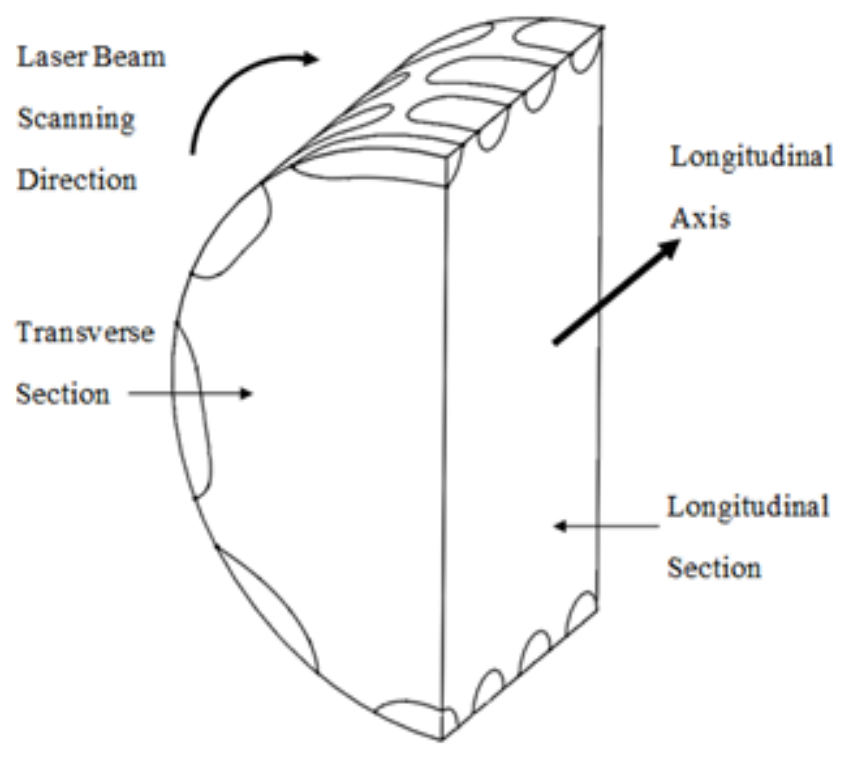



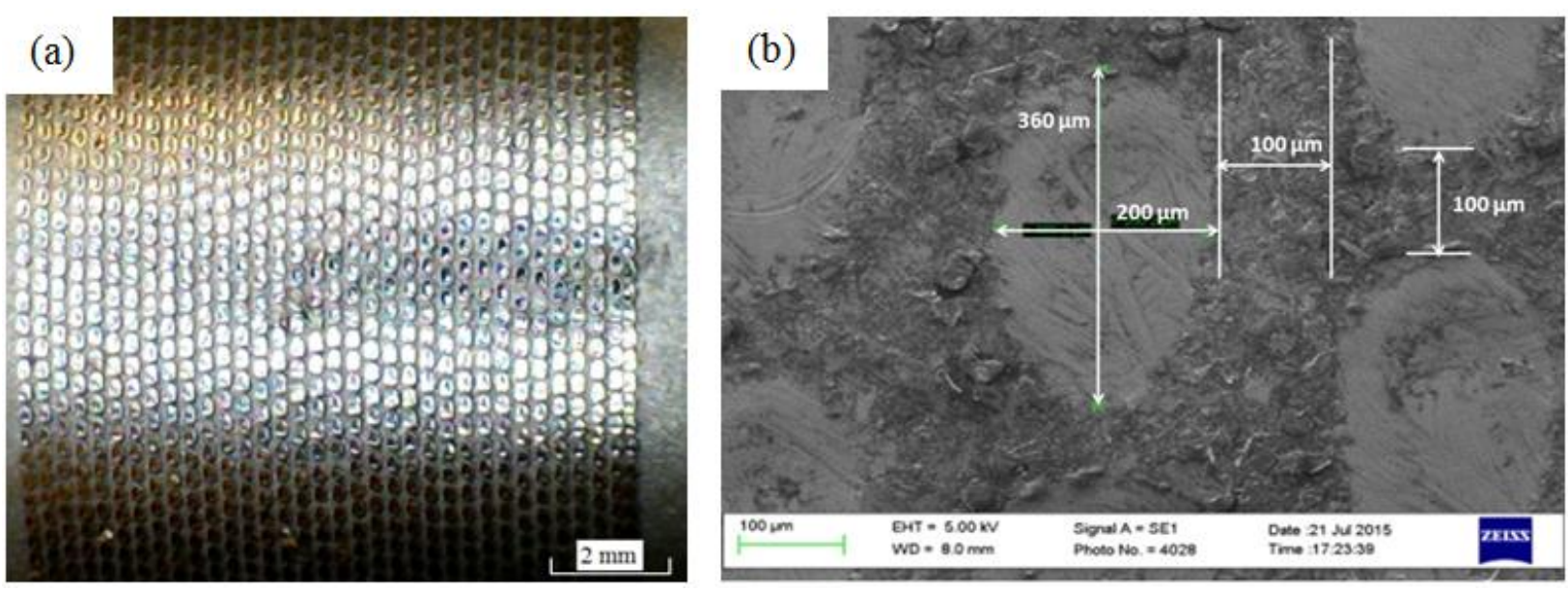


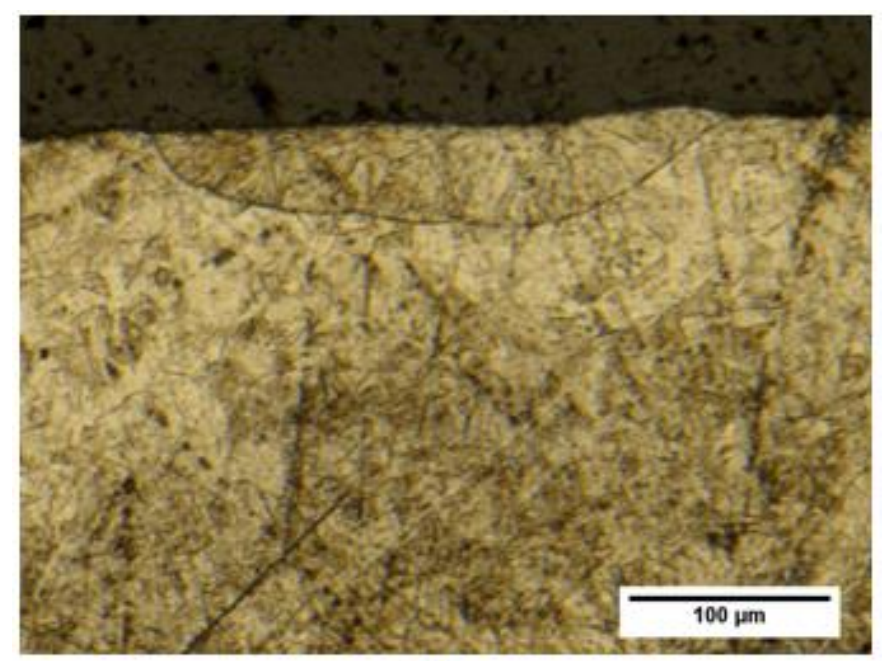

(a)

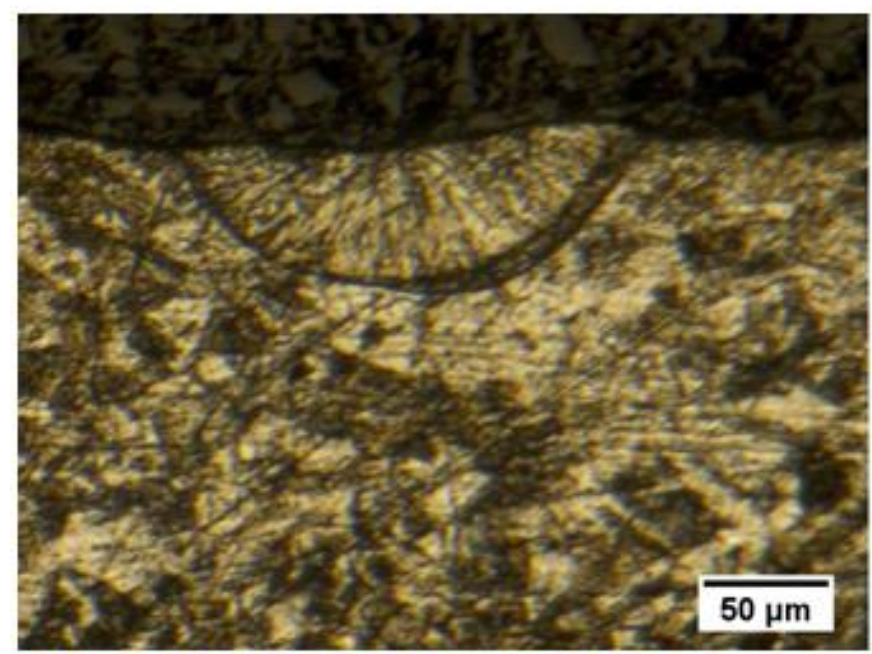

(b)

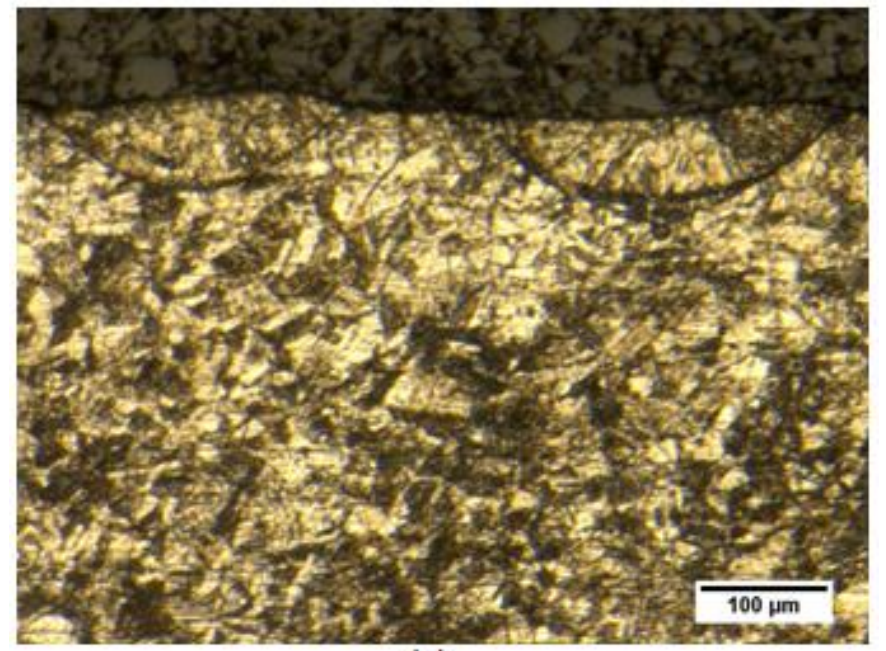

(c) 


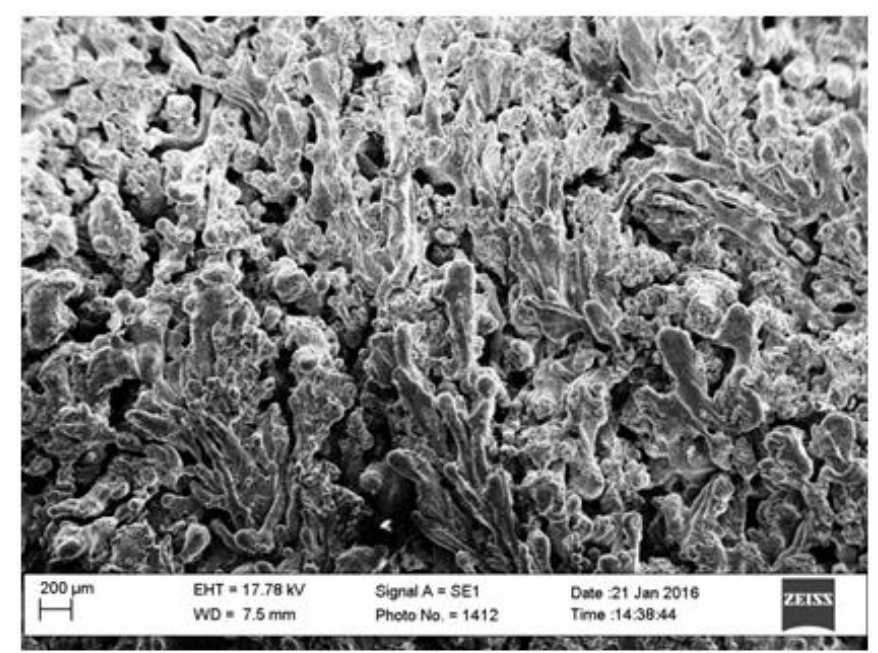

(a)

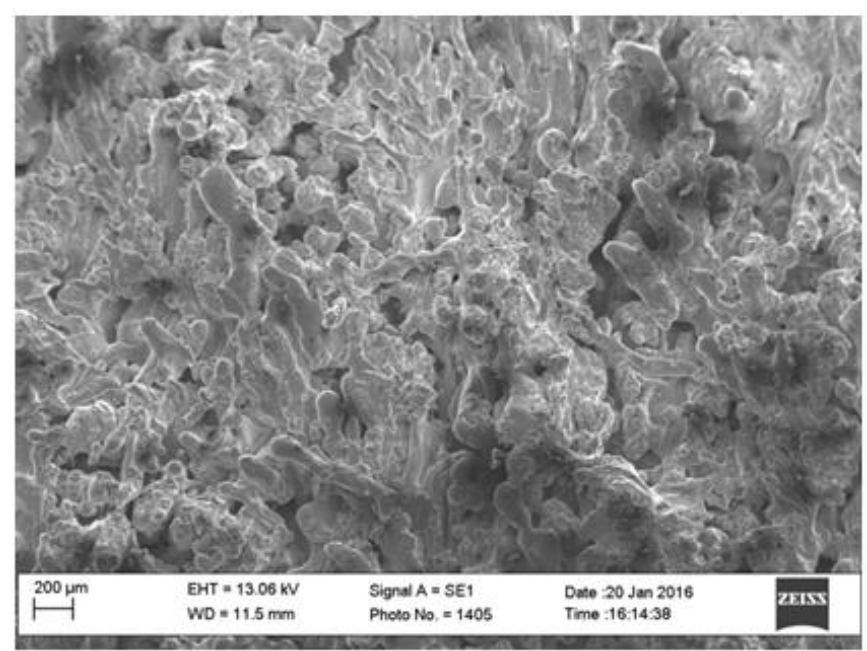

(b)

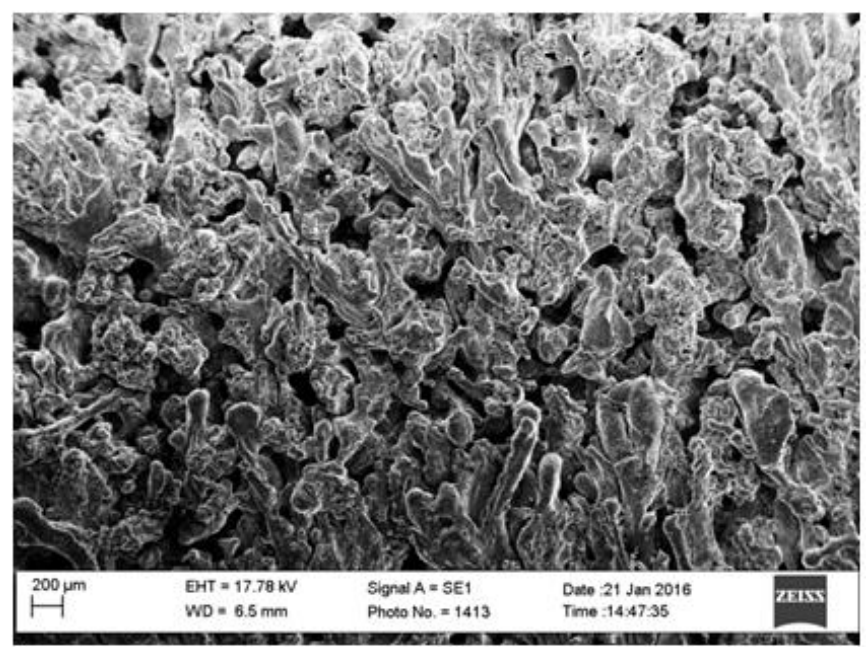

(c) 

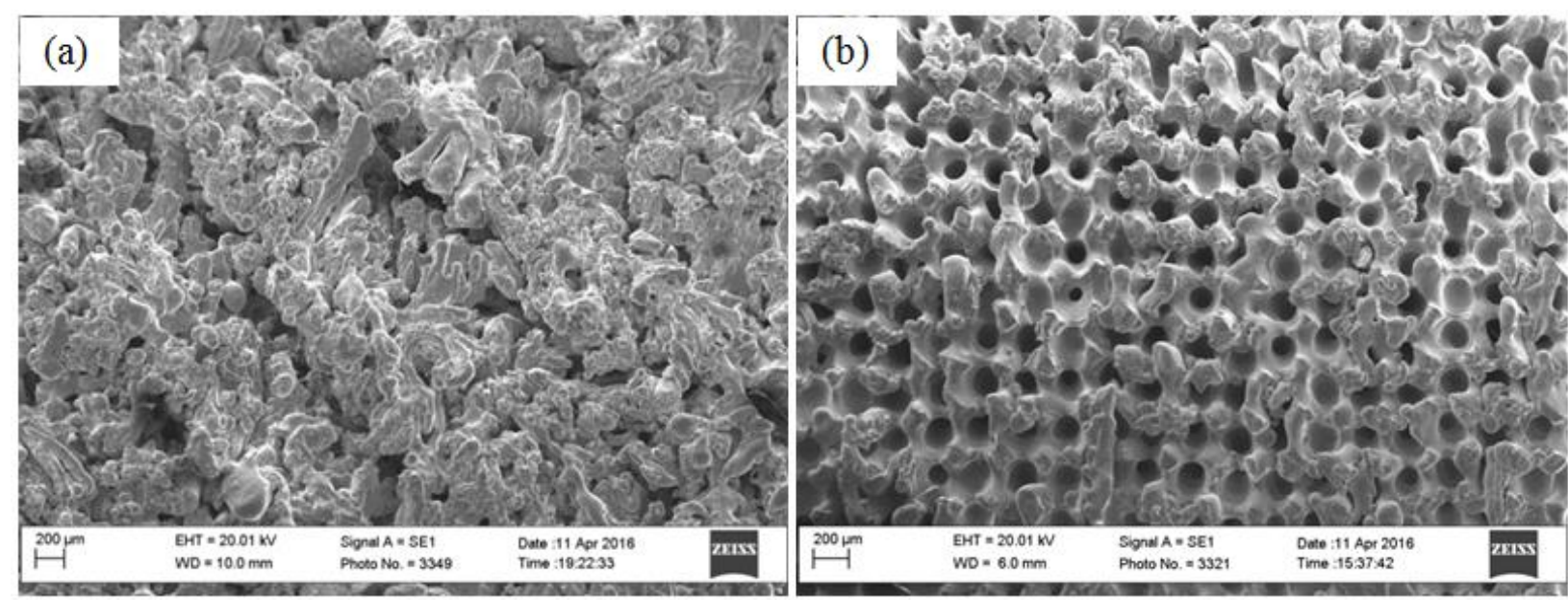


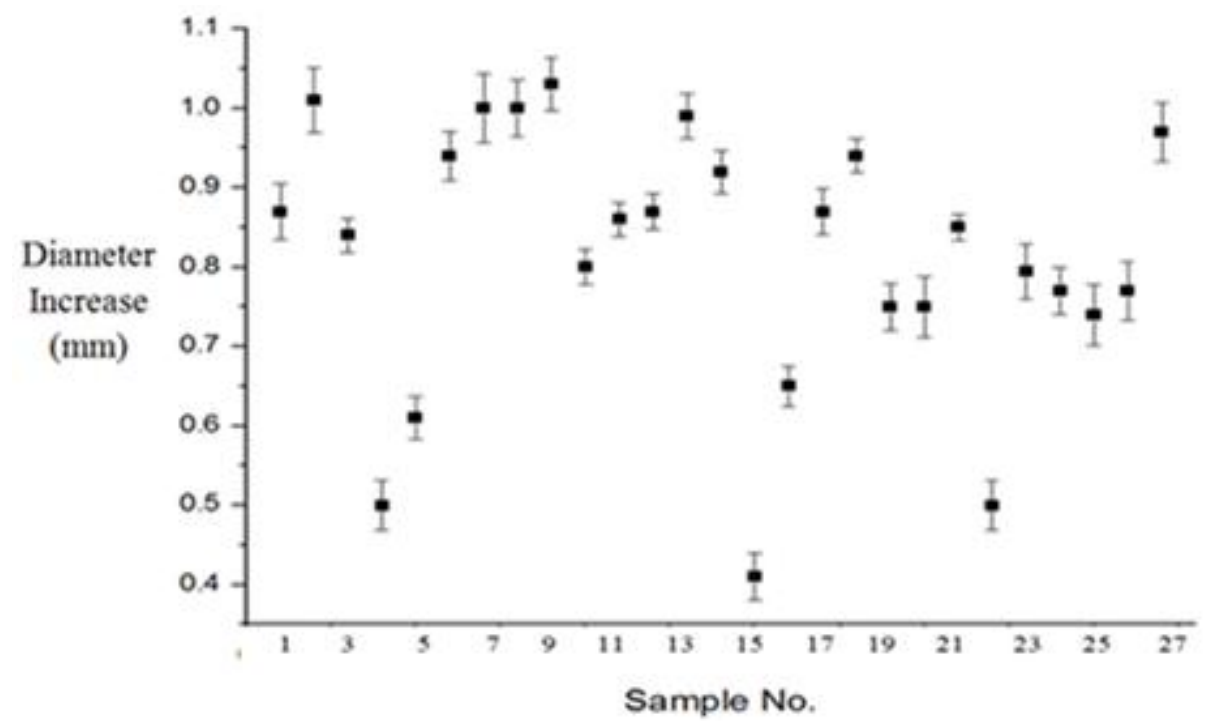

12 


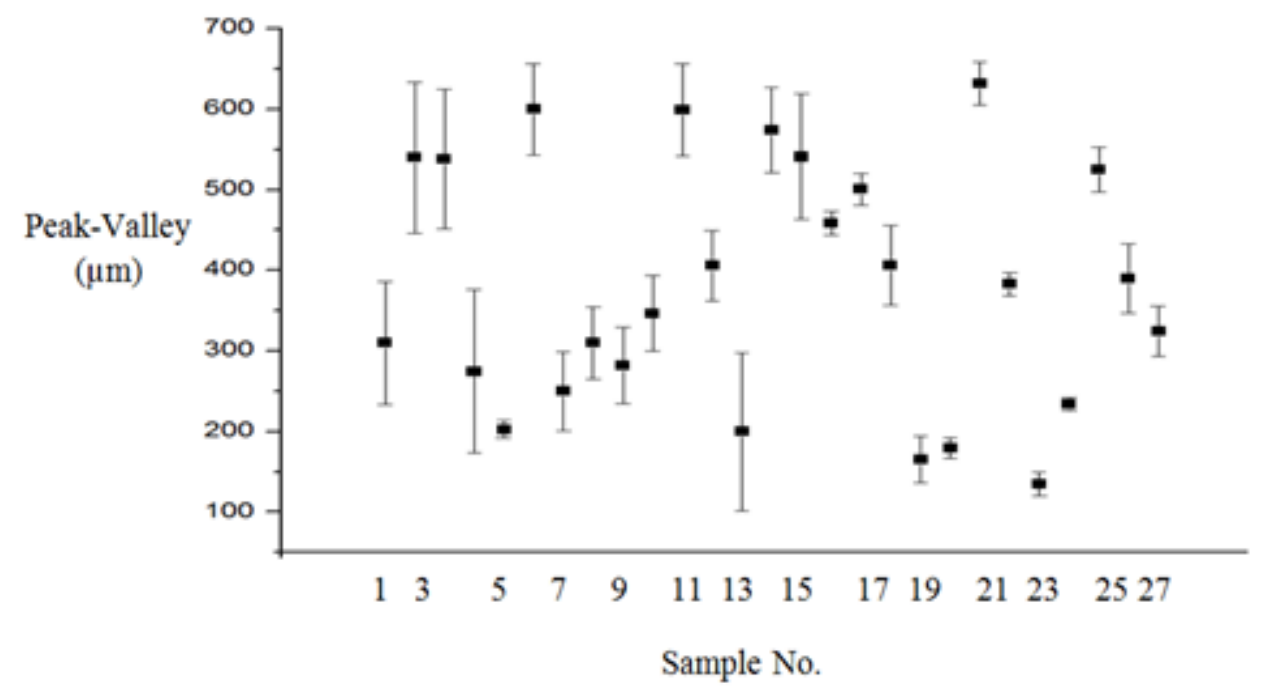

13 


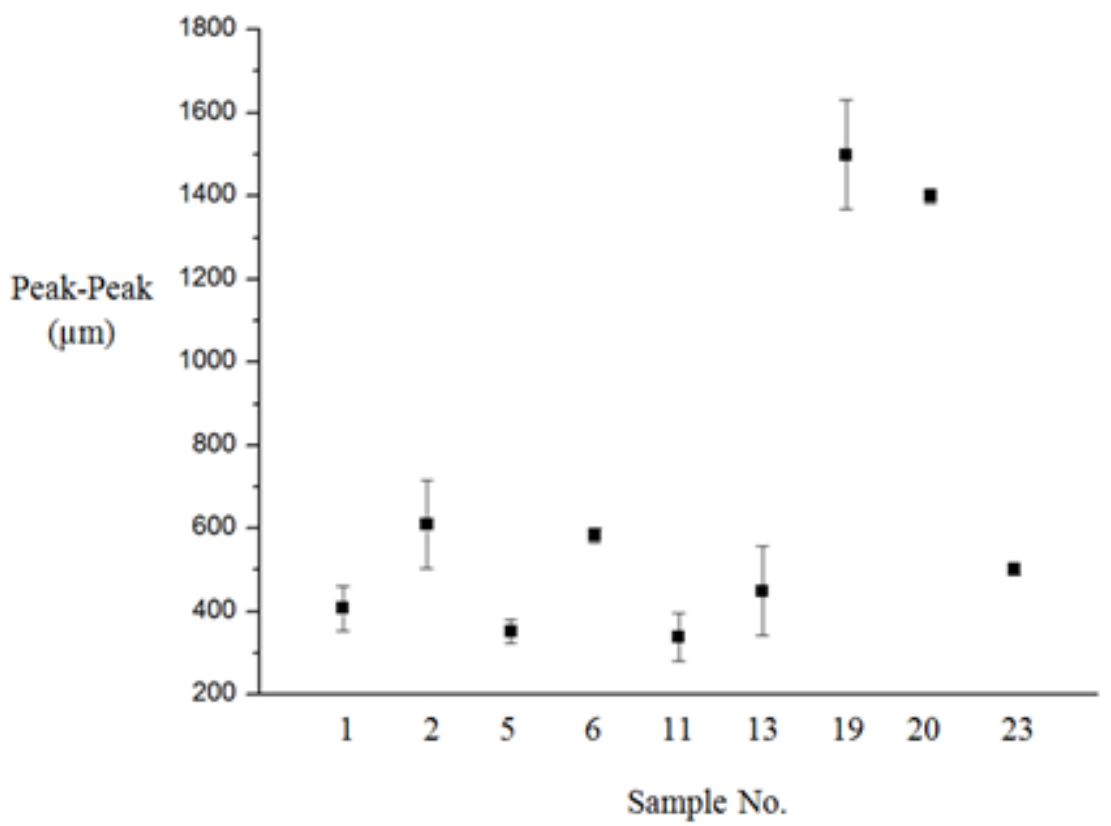

14 


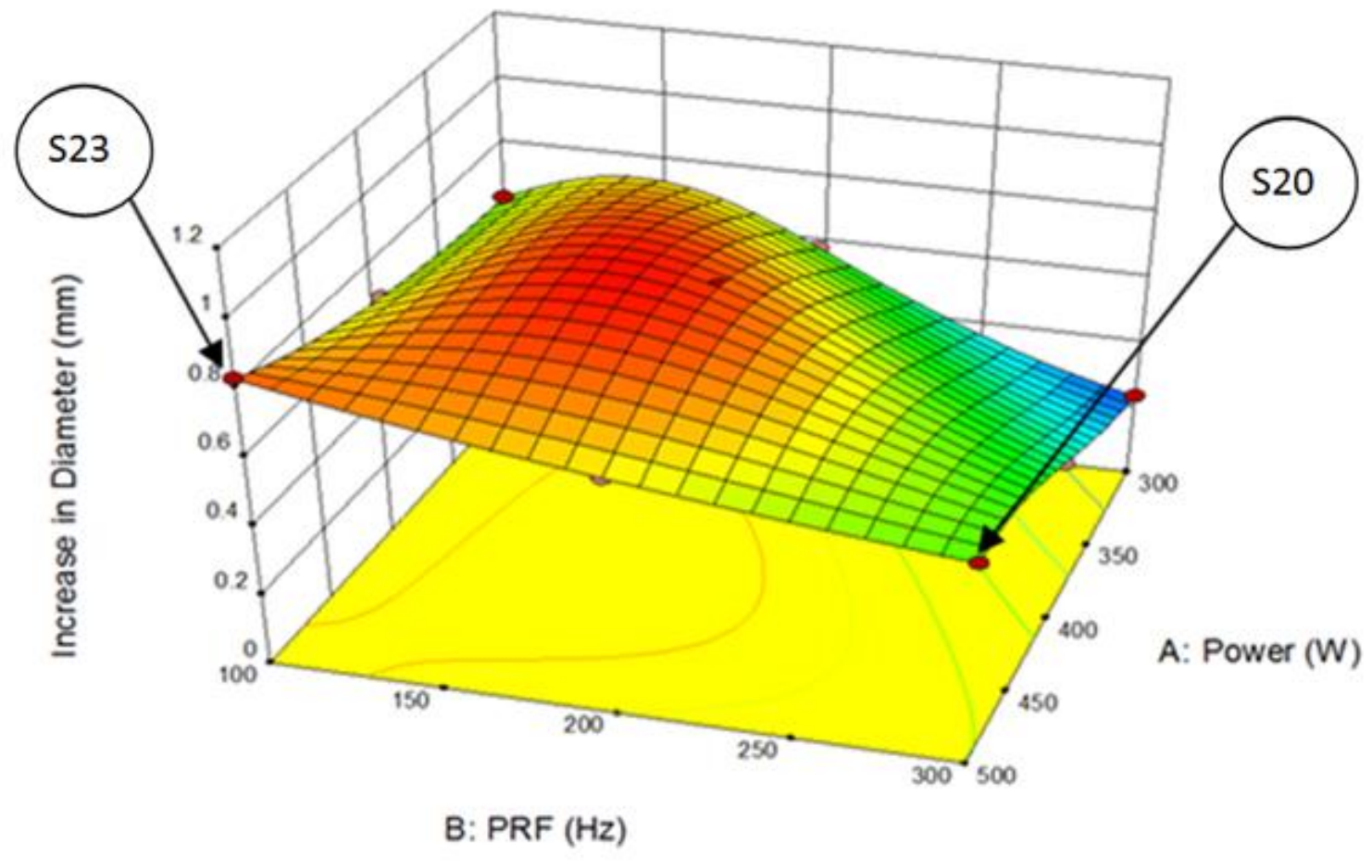

15 


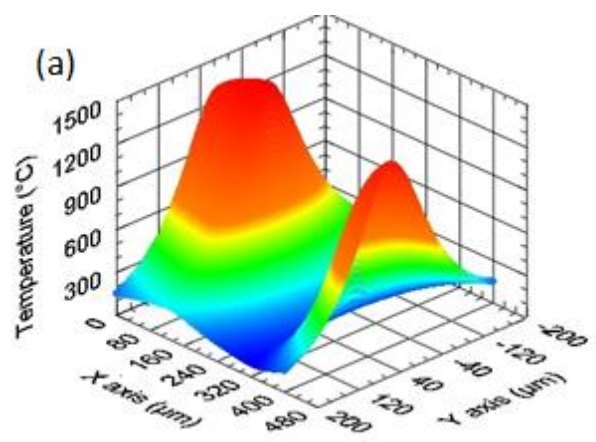

(b)

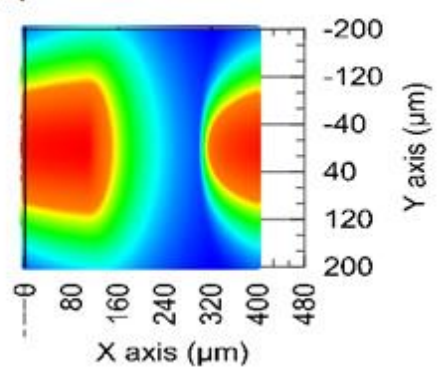

(c)

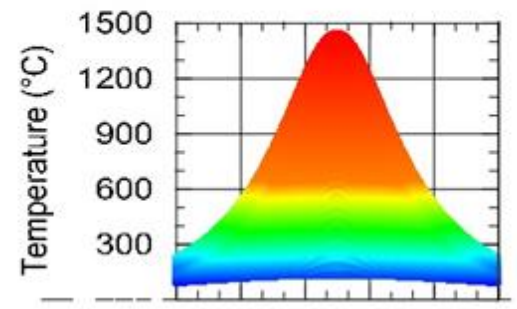

16 


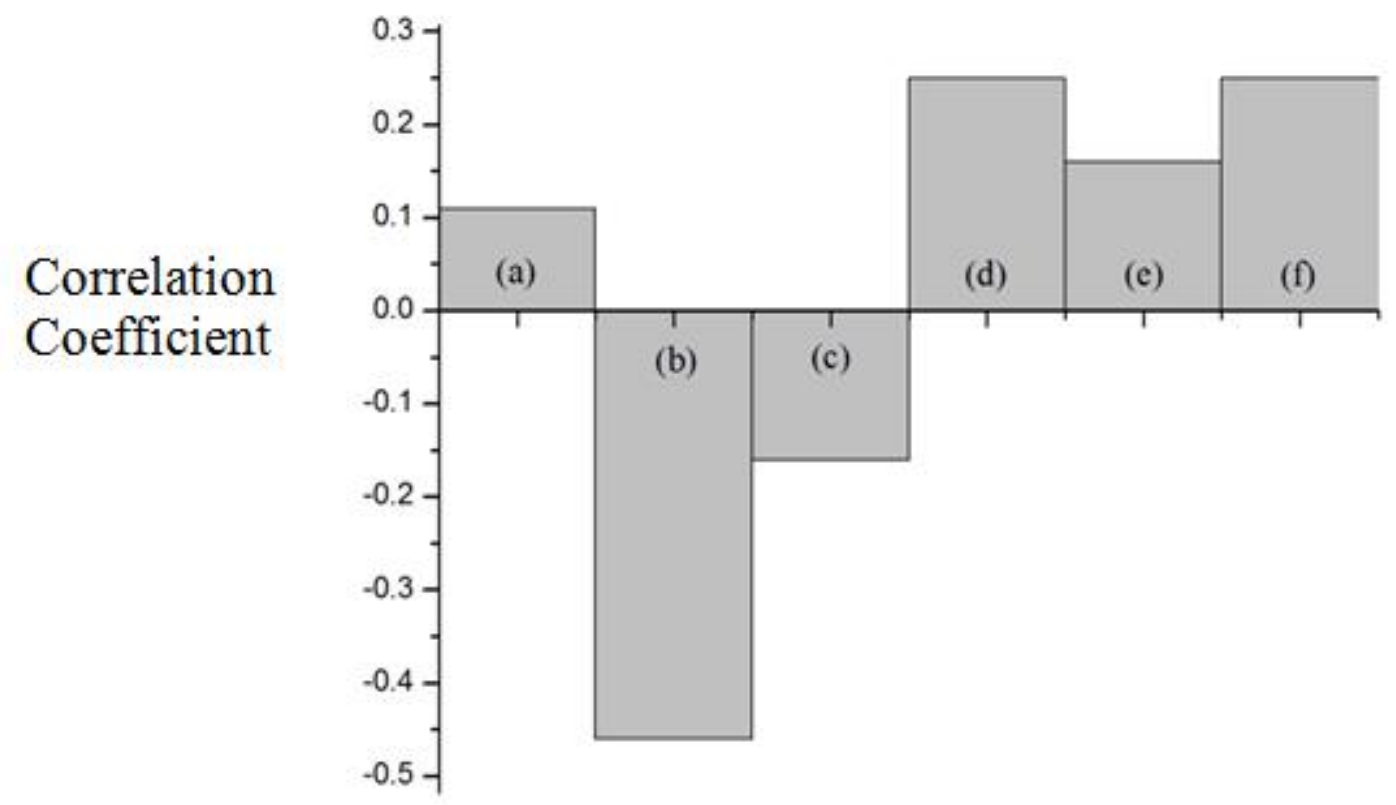

17

Link to paper:

http://www.sciencedirect.com/science/article/pii/S0257897216309616 